\title{
Obesity trends and determinant factors in Latin America
}

\author{
Tendencias en la obesidad y factores \\ determinantes en América Latina
}

Juliana Kain 1

Fernando Vio 1

Cecilia Albala 1

1 Instituto de Nutrición y Tecnol ogía de los Alimentos, Universidad de Chile. Casilla 138-11, Santiago, Chile. jkain@uec.inta.uchile.cl

\begin{abstract}
Obesity rates have increased markedly in Latin America, especially during the last 1015 years, becoming a public health problem in most countries. Prevalence of obesity among preschool children remains low, while among schoolchildren it has increased considerably. Prevalence is high in the adult population, especially among women with less schooling. In developed populations, obesi ty occurs more frequently among the poor; the opposite occurs in less developed societies, where in households undergoing nutritional transition, underweight can coexist with obesity. The most important determinant factors invol ved in the increasing obesity prevalence are fetal and infant nutritional conditions (stunting), education and socioeconomic conditions, dietary changes (especially increased total energy intake), and physical inactivity. Because chronic di seases are the main causes of death in the Region and obesity is one of the main risk factors for these di seases, policies to improve economic and educational levels with the implementation of health promotion and prevention should be a priority in every country.

Key words Obesity; Nutritional Status; Risk Factors
\end{abstract}

Resumen En América Latina la obesidad ha aumentado considerablementellegando a convertirse en un problema de salud pública en casi todos los países. La prevalencia de obesidad es baja entre los preescol ares, pero ha aumentado si gnificativamente entre los escolares. En los adultos, la preval encia es al ta, especial mente entre las mujeres con menor educación. En sociedades más desarrolladas, la obesi dad aparece más frecuentemente entre los pobres, lo opuesto ocurre en poblaciones pobres, donde, además, puede coexistir la desnutrición junto a la obesidad. Los factores de ri esgo más importantes rel acionados con el incremento de la obesi dad son: las condiciones fetales y la situación nutricional durantela infancia (talla baja), características socioeconómi cas y nivel educacional, aspectos dietéticos y la inactividad física. Por ello, y debido a que las enfermedades crónicas constituyen la principal causa de muerte en todos los países de la región, y la obesi dad es uno de los princi pal es factores de riesgo de éstas, la implementación de políticas y programas que apunten mejorar la si tuación económica y educacional de los más pobres y al mismo tiempo cambiar los hábitos de vida de toda la población es absolutamente prioritario.

Palabras clave Obesidad; Estado Nutricional; Factores de Riesgo 


\section{Introduction}

Latin America is undergoing a rapid demographic, epidemiological, and nutritional transition. Improvements in overall socioeconomic status (SES) and health and educational indicators are occurring in most countries. The epidemiological transition has been characterized mainly by the urbanization process, which has produced deleterious effects on the dietary and physical activity patterns of the population (Popkin, 1998). In terms of diet, rural inhabitants tend to eat traditional diets that are high in grains, fruits, and vegetables; when they move to the cities they increasingly adopt a "Western-type" diet, high in fat and refined sugars. These changes, accompanied by a marked increase in sedentary behavior, are the primary risk factors for the explosive rise in obesity, which together with an increase in the consumption of tobacco and alcohol and stress-related ailments are associated with the rising prevalence of non-communicable chronic diseases (NCCD) (Popkin et al., 1995). In fact, these diseases together constitute the first cause of death in every Latin American country. It is important to point out that of all the risk factors associated with mortality from NCCD, obesity is the one that has undergone the largest increase and is now the main nutritional disease in most Latin American countries (Uauy et al., 2001).

\section{Obesity prevalence in Latin America}

Obesity in preschool and schoolchildren

Information on obesity trends in Latin America is normally limited to preschool children and childbearing-age women. Martorell et al. (1998, 2000) reviewed national surveys conducted from 1982 onward to assess maternal and child obesity in Latin America. Most of the data were obtained from the Demographic and Health Surveys Institute for Resource Development (DHS/IRD); of the 26 data sets used, 16 came from DHS/IRD. Obesity in children was defined as weight-for-height $>2 Z$ (WHO, 1995).

Results show that obesity preval ence with data derived from cross-sectional surveys from different Latin American countries is quite low. This is especially true in less developed countries, such as Guatemala (1.7\%), Honduras (1.4\%), and Bolivia (2.1\%). Obesity was more prevalent among girls; residence in urban areas, high SES, and higher maternal schooling were associated with higher childhood obesity prevalence in most countries. One important point stressed by the authors is the fact that national prevalence figures do not reflect regional differences, which exist especially in larger countries like Mexico and Brazil.

Other authors (De Onis \& Blössner, 2000) have also determined the obesity prevalence in Latin American preschool children. The analysis was based on national survey data collected from 1970 until their publication. The data originated from the WHO Global Database on Child Growth and Malnutrition (De Onis \& Blössner, 1997). For all the Latin American countries, the data reported are based on samples, except for Argentina, Chile, Uruguay, and Venezuela, where estimates were based on national nutrition surveillance systems. Table 1 shows the latest figures for most Latin American countries.

As shown in Table 1, Argentina, Chile, and Costa Rica have the highest rates (7.3, 7.0, and $6.2 \%$ respectively), while the lowest prevalence is observed in less developed countries, such as Haiti and Bolivia.

It is important to point out that although the sources from which these two studies based their analyses are different, both rely primarily on national samples conducted during the same or similar periods, but the results turn out to be quite different in some countries. This makes it difficult for policy-makers and others to obtain a clear picture of the situation.

Table 1

Latest national prevalence of obesity in preschool children by country.

\begin{tabular}{lc}
\hline Country (year) & \% obese* \\
\hline Argentina (1994) & 7.3 \\
Bolivia (1998) & 6.5 \\
Brazil (1996) & 4.9 \\
Chile (1996) & 7.0 \\
Colombia (1995) & 2.6 \\
Costa Rica (1996) & 6.2 \\
Dominican Republic (1996) & 2.8 \\
El Salvador (1993) & 2.2 \\
Guatemala (1995) & 4.0 \\
Haiti (1994-1995) & 2.8 \\
Mexico (1988) & 3.7 \\
Paraguay (1990) & 3.9 \\
Peru (1996) & 6.4 \\
Uruguay (1992-1993) & 6.2 \\
Venezuela (1997) & 3.0 \\
\hline
\end{tabular}

* weight for height $>2 \mathrm{ZWHO}$.

Source: De O nis \& Blössner (1997). 
Monteiro et al. (2002) analyzed four nationwide Brazilian surveys (1975, 1989, 1996, and 1997) conducted in the Northeast, the country's most economically disadvantaged region, and the Southeast, the most economically advanced. These surveys included anthropometric data for both young children and adults.

Figure 1 shows the trends in average overweight prevalence for children 1-4 years of age by region and for both regions combined (reported as country prevalence, as the Northeast and Southeast include approximately $70 \%$ of the total Brazilian national population).

As the authors point out, according to these results the Brazilian national obesity prevalence is quite low and remained practically unchanged over the years. The rates are higher in the more developed Southeast, and although they increased in this region over time, the rate of increase was not significant.

Although obesity among preschoolers may not be a public health problem in developing countries, it is definitely a problem in schoolchildren from post-transitional countries. Such is the case in Chile, for example, where undernutrition has virtually been eradicated, while obesity prevalence in school-age children has shown an impressive rise (Albala et al., 2001; Kain et al., 2002). Figure 2 shows that the obesity prevalence among boys attending first grade increased from $6.5 \%$ in 1987 to $17 \%$ in 2000 ; in girls, from $7.8 \%$ to $18.6 \%$. These figures are indicative of a significant problem, compromising not only their future health as adults but also their present health.

$\underline{\text { O besity in adults }}$

An analysis of the nutritional situation of Latin American women (15-49 years) also derived from the same DHS/IRD datasets described previously is presented for selected countries (Martorell et al., 1998). Table 2 presents the obesity prevalence in women (defined as a BMI cut- off of $\geq 30 \mathrm{~kg} / \mathrm{m}^{2}$ ).

The lowest prevalence was found in some of the poorer nations, including $\mathrm{Haiti}$, Bolivia, and Honduras. The authors found that more schooling was associated with obesity in Haiti, Guatemala, and Peru, while in other poor nations such as Bolivia and the Dominican Republic, this association was not present.

In general, an increasing obesity prevalence in women was found in countries with higher per capita income and in those with lower rates of stunting in children. A recent WHO (World Health Organization)/PAHO (Pan-American Health Organization) publication on obesity in
Figure 1

Secular trends in the average prevalence of obesity (\%) for 1-4 year-old children by Region. Brazil, 1975-1996.

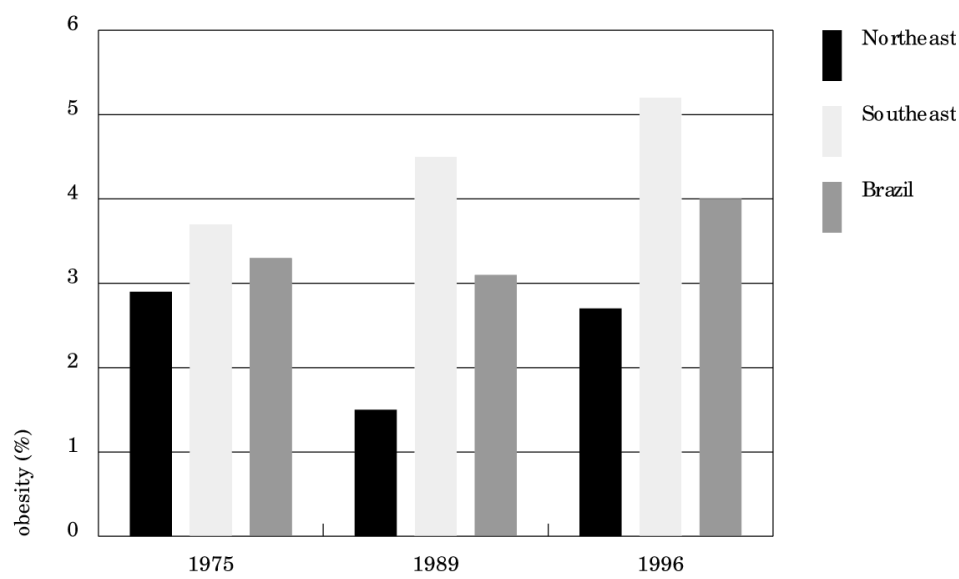

Source: Monteiro et al. (2002).

Latin America (Peña \& Bacallao, 2000) revealed an increasing trend in obesity as countries emerge from poverty, especially in urban areas. In contrast, in middle-income countries and even more in developed countries, obesity tends to decline as income increases, especially for women (Aranceta et al., 2001).

Monteiro et al. (2002) also analyzed the adult population (20 years and older) based on the four nationwide surveys from Brazil described above. The authors determined the age-adjusted obesity prevalence by gender for the Northeast and the Southeast regions. Table 3 shows these results.

The table shows that the prevalence of obesity increased in both genders. At the national level, the rate for women was almost double that of men. As discussed by the authors, in the last period, obesity in women increased in the poorer region, while it declined for those in the more developed region. Not shown here, but reported by the authors, is the fact that in higher-income women from the Northeast and in lower-income women from the more developed Southeast, the rate of increase was dramatic and exactly the same, from $6 \%$ to $14 \%$ in 20 years.

Monteiro et al. (2000a) also point out that there has been limited evidence on the trends in obesity, especially related to social class. The three national surveys described above have provided important information regarding sec- 
Figure 2

Trends in the prevalence of obesity of Chilean first-grade children*.

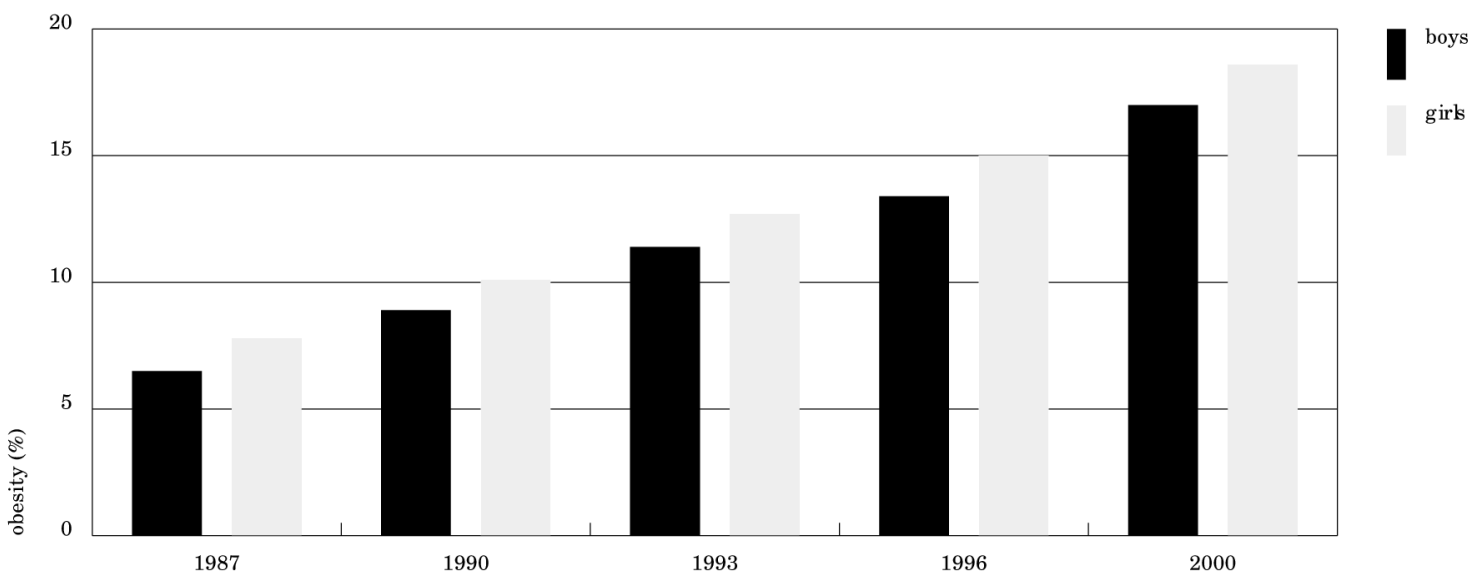

* O besity is defined with a weight/height $>2 Z$ WHO reference.

Source: Albala et al. (2002).

Table 2

Prevalence of obesity in women from selected Latin American countries.

\begin{tabular}{lc}
\hline Country (year) & Women $(\%)^{*}$ \\
\hline Bolivia (1994 & 7.6 \\
Brazil (1996) & 9.7 \\
Colombia (1995) & 9.2 \\
Dominican Republic (1996) & 12.1 \\
Haiti (1995) & 2.6 \\
Honduras (1996) & 7.8 \\
Guatemala (1995) & 8.0 \\
Mexico (1987) & 10.4 \\
Peru (1996) & 9.4
\end{tabular}

* $\mathrm{BMI}=30$.

Source: Martorell et al. (1998).

ular trends in obesity among adults in various settings and socioeconomic conditions. The analyses of these surveys show that from 1975 to 1989 , the evidence is clear that obesity among adult males and females increased among all age groups, but in the last period, although the prevalence also increased in both genders, the upward trend was only clear in men for all age groups. In fact, for women the increase was statistically significant only for the first period. In terms of socioeconomic status and urban/ rural setting, Table 4 shows that obesity prevalence was higher in urban areas, especially among all lower-income men and women. Particularly important is the fact that in women from higher-income groups, obesity declined during the last period in both rural and urban settings and was statistically significant only in urban areas ( $28 \%$ reduction).

According to a recent publication by Rivera et al. (2002), the more developed industrial States in the North of M exico have very similar epidemiological indicators to those observed in developed countries, while the less developed Central and Southern Mexican States exhibit pre-transitional conditions. The National Nutrition Survey carried out in 1988 and 1999 (Instituto Nacional de Salud Pública, 1999) showed that the national overweight prevalence (BMI $\geq 30$ ) for adult women increased significantly, from $9.4 \%$ in 1988 to $24.4 \%$ in 1999. Figures at the regional level were markedly different; in the North, the more affluent region, these rates increased from $11.8 \%$ to $31.3 \%$, while in the South they increased from $8.2 \%$ to $20.8 \%$. These results show that although the prevalence is lower in the South, the rate of increase in the period was the same. This same survey also includes anthropometric data on infants and preschool children. In this age bracket as a whole, obesity prevalence at the national level determined as a weight-for-height $>2 \mathrm{Z}$ score (WHO) was initially $4.2 \%$, increasing to $5.3 \%$ in 1999 . Although the highest prevalence rates were observed in the North, the rel- 
Secular trends in the prevalence of obesity in Brazilian adults by region.

\begin{tabular}{lcccccc}
\hline Region & & \multicolumn{2}{c}{ Obesity prevalence (\%)* } & Female \\
& 1975 & $\begin{array}{l}\text { Male } \\
1989\end{array}$ & 1997 & 1975 & 1989 & 1997 \\
\hline Northeast & 1.2 & 2.4 & 4.4 & 4.1 & 7.8 & 12.5 \\
Southeast & 2.9 & 5.8 & 8.4 & 7.8 & 14.0 & 12.3 \\
Brazil & 2.1 & 4.1 & 6.4 & 6.0 & 10.9 & 12.4 \\
\hline
\end{tabular}

$* \mathrm{BMI} \geq 30$.

Source: Monteiro et al. (2002).

Table 4

Secular trend in age-adjusted prevalence of adult obesity (\%) by gender, socioeconomic level, and setting. Brazil, 1975-1997.

\begin{tabular}{lcccccc}
\hline $\begin{array}{l}\text { Setting and family } \\
\text { income }\end{array}$ & 1975 & $\begin{array}{c}\text { Males } \\
1989\end{array}$ & 1997 & 1975 & $\begin{array}{c}\text { Females } \\
1989\end{array}$ & 1997 \\
\hline $\begin{array}{l}\text { Rural } \\
\text { 1st Q uartile }\end{array}$ & 0.6 & 0.6 & 1.2 & 1.5 & 4.4 & 8.1 \\
$\quad$ 4th Q uartile & 2.1 & 2.6 & 5.1 & 7.7 & 12.5 & 11.2 \\
Urban & & & & & & \\
$\quad$ 1st Q uartile & 1.8 & 3.6 & 4.7 & 6.5 & 10.2 & 14.1 \\
4th Q uartile & 4.8 & 8.4 & 9.4 & 7.8 & 12.8 & 9.2 \\
\hline
\end{tabular}

Source: Monteiro et al. (2000).

ative changes were much larger in the South, the less developed area.

In Chile, the nutritional situation of adults has been studied in pregnant women who have their regular prenatal check-ups in the public health care system (with a coverage of $70 \%$ ) and also in large samples of the general population from Santiago and Valparaiso (the country's two largest cities). Among pregnant women, prevalence of obesity parallels that observed among schoolchildren, increasing from $12.9 \%$ in 1987 to $32.7 \%$ in 2000 (Uauy et al., 2001). With regard to the adult population, two surveys conducted in 1988 and 1992 in Santiago (Berríos, 1994), showed a marked increase in obesity, from $6 \%$ to $11 \%$ in men and from $14 \%$ to $24 \%$ in women over the four-year period. In Valparaiso, a study on risk factors for chronic diseases in 1997 showed obesity prevalence rates of $15.7 \%$ for men and $23 \%$ for women (Jadue et al., 1999). Figure 3 shows how the prevalence of obesity varies with age, gender, and socioeconomic status in this sample. With regard to gender and age, prevalence is much higher for women, and increases with age. In fact, in the 55-64 age-category, $27 \%$ of men and $30 \%$ of women are obese. Both men and women of high SES have lower prevalence rates. This situation repeatedly appears in post-transitional societies and developed countries, such as Spain, where older, low-income women with less schooling appear to be the most susceptible group to weight gain (Aranceta et al., 2001).

\section{Determinant factors in increasing prevalence of obesity}

Low birth weight and stunting

Several studies have shown a relationship between fetal and infant nutritional conditions and adult-onset diseases. This is reflected by the higher incidence of obesity among men whose mothers experienced food deprivation during pregnancy, as reported by Barker (1994). 
Figure 3

Prevalence of obesity* according to age, gender, and socioeconomic status (SES). Valparaiso, Chile, 1997.

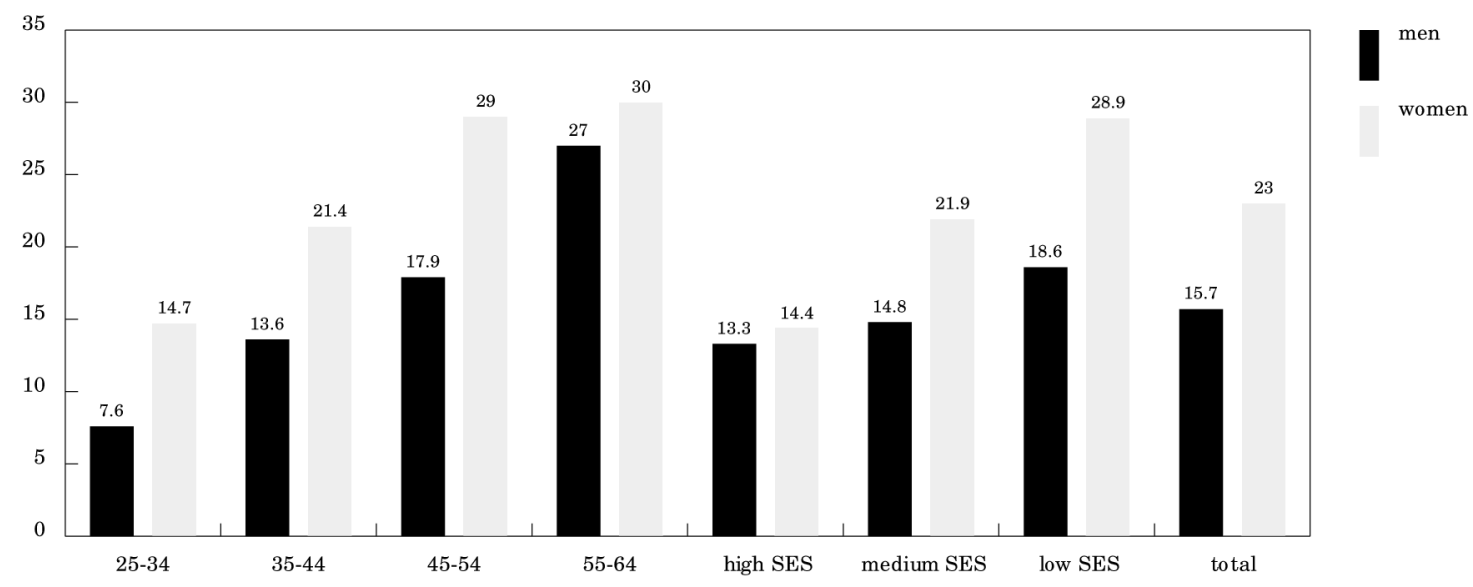

* Prevalence of obesity BMI $>30$.

The latter author shows that children with low birth weight are more likely to develop abdominal obesity and other diseases related to Syndrome $X$ during adulthood. This is especially true if a rapid weight gain occurs in the first years of life (Popkin, 1998). On the other hand, stunting has been associated with both metabolic and physiological risk factors for obesity. Popkin et al. (1996) examined this relationship for children aged 3-6 and 7-9 years in nationally representative surveys from Russia, Brazil, South Africa, and China. Results showed that income-adjusted risk ratios for overweight in a stunted child ranged from 1.7 to 7.8 . Hoffman et al. (2000) reported in a study of stunted Brazilian children that they oxidized a lower proportion of energy as fat, in comparison with healthy children. The same risk factor for obesity has been shown in other risk populations. Schroeder et al. (1999) showed in a populationbased cohort study of Guatemalans born into low-income environments that childhood stunting was associated with a future increase in abdominal fat. This study also demonstrated that migration to urban areas increased this positive association in severely stunted women. The data are consistent with those of Sichieri et al. (2000), based on a survey in Rio de Janeiro, showing an increased risk of obesity among short women, with short stature being a marker for early undernutrition. The authors concluded that in countries where maternal and child malnutrition coexists with urbaniza- tion and economic growth, obesity and related chronic diseases are likely to increase.

Also in Brazil, a study conducted in destitute neighborhoods of Maceió, a city in the Northeast (Florencio et al., 2001), showed that among children ( $<10$ years), prevalence of wasting and stunting was high, with no overweight. In adolescents, prevalence of undernutrition was also important, with a low prevalence of overweight. Meanwhile, in adults, prevalence of overweight was higher than that of underweight. An association was found between stunting and current overweight in adults: among stunted adults, 30\% were overweight. This study concluded that in $30 \%$ of households, undernutrition coexisted with overweight. "These results may indicate that better living conditions in urban areas in a population 'adapted' to chronic famine might increase the susceptibility to obesity" (Florencio et al., 2001:277). The same phenomenon has been reported in other countries as well. Doak et al. (2000) found that urban households in China and Russia with an underweight member also frequently included an overweight person. The proportion of this type of household in the three countries was related to the nutritional transition. The proportion was highest in Brazil, probably due to a more rapid transition. In Chile, undernutrition and obesity also coexisted during a period of rapid transition in the 1980 s, when a high proportion (40\%) of mothers of undernourished children attending nu- 
trition recovery daycare centers were found to be obese (Albala et al., 1986; Vio et al., 1985).

\section{Education and socioeconomic status}

Developing countries undergoing the nutritional transition exhibit lower adult obesity rates among higher income groups, just as developed countries. Education, which is associated with socioeconomic status and can be used as a proxy for income, has also been shown to influence BMI (especially in women). It is likely that the influence of education on dietary intake, obesity, and cardiovascular risk factors change with time, depending on the country's degree of economic development. Initially, increasing education (and probably income) may be associated with a less healthy diet; over time, the association becomes reversed. This appears to be the situation in Hong Kong, where Woo et al. (1999) in a study on an adult Chinese population found that BMI and waist-hips ratio were lower with increasing levels of education in women, probably related to a healthier diet consumed by these women.

Monteiro et al. (2001) further analyzed the 1997 survey to determine if there was an independent effect of income and education on risk of obesity. They found that risk of obesity in men strongly increased with income in the two regions. Level of education did not increase the risk of male obesity in the less developed region but, in the more developed one, bettereducated men had slightly less chance of becoming obese. In the Northeast, obesity in women was associated with both income (directly) and education (inversely), while in the Southeast, only education influenced the risk of obesity, and a reduction in obesity prevalence was reported among upper-income urban residents (Table 4). This reduction was associated with regular physical exercise by highincome urban women $(26.3 \%$ of these women exercised on a weekly basis as compared to $2.8 \%$ in the lowest-income urban quintile). The authors concluded that in transitional societies, income is a risk factor for obesity, whereas educational level is protective. The association between these variables and obesity depends on gender and the level of economic development.

An improvement in educational level, especially in women, is one way the rise in obesity rates may be attenuated, as is the case of Spain. From 1987 to 1997 the increase in obesity prevalence was less than expected (a possible explanation was the increase in years of schooling among Spanish women during the same peri- od) (Artalejo et al., 2002). This fact agrees with the decline in obesity observed in North Karelia and Kuopio, where the decline in female obesity was more evident in the upper socioeconomic groups (Monteiro et al., 2000b).

\section{Dietary factors}

Dietary factors are associated with the main causes of death in Latin American countries. As income increases, so does overall energy intake and that of total fat, especially saturated fat. On the other hand, consumption of cereals, legumes, and other fiber-rich foods such as vegetables and fruits has remained stable or even declined. The relative contribution of fat to energy intake as well as the type of fat consumed is closely related to the stage of the epidemiological transition (Popkin et al., 2001). Not only has there been a shift in the type of diet as explained above, but the rate of change in Latin America is accelerating (Popkin, 2001) and the burden of a high energy-dense diet is greater among the poor.

In general, countries with the highest consumption of saturated fat have a higher prevalence of cardiovascular diseases and diet-related chronic diseases. Table 5 depicts trends in per capita daily availability of Kcal and animal and vegetable fat for Chile, M exico, Guatemala, Brazil, and Haiti over the past two decades based on United Nations Food and Agricultural Organization (FAO) food balance information. Haiti, the poorest country in the Region, has the lowest per capita availability of Kcal and fat, with Guatemala having the second lowest. In all countries except Haiti, in spite of exhibiting acceptable percentages of Kcal from fat (around $27 \%$ ), relative to developed countries there has been a marked increase as shown in $\%$ change. The most impressive increases in the availability of animal fat have occurred in Brazil and Chile ( $72 \%$ and $55.4 \%$, respectively).

Table 5 shows data on average per capita availability for the country, which obviously is not equivalent to consumption. According to Sichieri (2000), in Rio de Janeiro, food consumption surveys show that in 1975 the mean percentage of dietary energy from fat was $26 \%$ and that it only rose to $26.6 \%$ in men and $28 \%$ in women, while there was an impressive increase in obesity. Recent data in the same city suggest that consumption of all foods has increased, and that the association with obesity is stronger with total calorie intake than with fat. In Brazil and probably in other transitional societies (M onteiro et al., 2000a), apart from the increase in dietary fat and the decline in com- 
Table 5

Availability of total calories and vegetable and animal fat in selected Latin American countries, 1979, 1989, and 1999 .

\begin{tabular}{|c|c|c|c|c|}
\hline & 1979 & 1989 & 1999 & Change $(\%)$ \\
\hline \multicolumn{5}{|l|}{ Chile } \\
\hline Kcal/day per capita & 2,660 & 2,485 & 2,858 & +7.4 \\
\hline$\%$ as fat per capita & 19.9 & 21.4 & 26.6 & +33.7 \\
\hline Vegetable fat $\mathrm{g} /$ day per capita & 30.1 & 26.0 & 39.8 & +32.2 \\
\hline Animal fat g/day per capita & 28.7 & 33.1 & 44.6 & +55.4 \\
\hline \multicolumn{5}{|l|}{ Mexico } \\
\hline Kcal/day per capita & 2,982 & 3,087 & 3,168 & +6.2 \\
\hline$\%$ as fat per capita & 22.8 & 23.6 & 26.1 & +14.5 \\
\hline Vegetable fat $\mathrm{g} /$ day per capita & 39.8 & 47.6 & 51.6 & +29.6 \\
\hline Animal fat g/day per capita & 35.9 & 33.4 & 40.2 & +12.0 \\
\hline \multicolumn{5}{|l|}{ Guatemala } \\
\hline Kcal/day per capita & 2,191 & 2,405 & 2,331 & +6.4 \\
\hline$\%$ as fat per capita & 17.4 & 17.0 & 19.7 & +13.2 \\
\hline Vegetable fat g/day per capita & 31.0 & 34.2 & 37.8 & +21.9 \\
\hline Animal fat g/day per capita & 11.4 & 11.2 & 13.2 & +15.8 \\
\hline \multicolumn{5}{|l|}{ Brazil } \\
\hline Kcal/day per capita & 2,707 & 2,784 & 3,012 & +11.3 \\
\hline$\%$ as fat per capita & 21.5 & 25.9 & 27.0 & +25.6 \\
\hline Vegetable fat g/day per capita & 38.7 & 49.0 & 45.6 & +17.8 \\
\hline Animal fat g/day per capita & 26.1 & 31.1 & 44.9 & +72.0 \\
\hline \multicolumn{5}{|l|}{ Haiti } \\
\hline Kcal/day per capita & 2,039 & 1,734 & 1,977 & -3.0 \\
\hline$\%$ as fat per capita & 14.6 & 14.2 & 16.4 & +12.3 \\
\hline Vegetable fat g/day per capita & 24.4 & 20.6 & 28.7 & +17.6 \\
\hline Animal fat g/day per capita & 8.6 & 6.7 & 7.4 & -14.0 \\
\hline
\end{tabular}

Source: FAO Food Balance Sheets. O btained from http://www.fao.org.

plex carbohydrates in the diet, the increase in the consumption of sugar has been significant.

Dietary factors are probably involved in the high prevalence of households with underweight children coexisting with one or more overweight adult. As reported by Doak et al. (2000), urban residence and income are involved. Urban residence is linked through the association with energy-dense diets, which have affected family members differently, due not only to the type of food but also to intrahousehold distribution.

\section{Sedentary lifestyle}

Sedentary behavior is one of the main risk factors of increasing obesity rates. Urbanization, on the other hand, is one of the main contributing factors to inactivity. People from low- er socioeconomic levels moving from rural areas to the cities generally adopt sedentary work, leaving behind active working lives involving heavy manual labor (Hoffman, 2001). Changes in activity patterns have been as rapid as dietary changes (Popkin, 2001). The decline in energy expenditure due to a change in labor practices can be substantial. The services sector has grown rapidly, while industrial production is dominated by capital-intensive processes with profound changes in time allocation patterns. Unfortunately, the work force is not only extremely sedentary in their jobs, but also at home, due to new household technologies (activity-saving appliances). In addition, a more profound shift has occurred in leisure activities (Popkin, 2001), namely excessive TV watching, computer games, and increased utilization of motor vehicles. For example, in Chile, the number of cars per 1,000 inhabitants was 38.9 in 1970, increasing to 136.6 in 1998, and the number of TV sets increased from 12,170 in 1970 to more than two million in 1998 (Albala et al., 2002). In Brazil, Monteiro et al. (2002) report that the services sector of the economy has increased markedly. The proportion of persons employed by this sector was $29 \%$ in 1970 , increasing to $55 \%$ in 1999. During the same period, Brazilian households with TV sets increased from $24 \%$ to $88 \%$.

Regarding the coexistence of under- and overnutrition in urban households, Doak et al., (2000) report that changes in both physical activity and diet are probably experienced differently by various family members. This, plus the influence of socioeconomic factors, results in some becoming underweight and others obese.

Data are scarce on sedentary behavior in all countries. A recent representative survey of the Chilean adult population (MINSAL, 2001) revealed that only $8.8 \%$ performed 30 minutes of regular physical activity three times a week. Men were slightly more active than women ( $11 \%$ versus $7 \%$ ). With respect to educational level, sedentary behavior increased as formal education declined.

A realistic way to attenuate rising obesity trends is to increase leisure-time physical activity, as observed in the Spanish population (especially women) by Artalejo et al. (2002). The authors speculate that this aspect, with the improvement in educational level, may have helped slow a rising trend in obesity that occurred in Spain during the last decade. 


\section{Conclusions}

Latin American countries are undergoing different stages of the epidemiological and nutritional transition. The poorer countries in the Region are still faced with the double burden of under- and overnutrition. As socioeconomic conditions improve, undernutrition declines and obesity increases. The most important determinants of obesity are fetal and infant nutritional conditions, especially stunting, economic and educational levels, and adoption of diets that are high in fat and sugar with declining physical activity (a consequence of the urbanization process). Obesity prevalence in preschool children is low, but increases in schoolchildren. In adults, women (especially those with less schooling) experience higher rates than men. In underdeveloped societies, obesity prevalence is higher among the higher socioeconomic groups. A new concern has emerged in underdeveloped societies, where households can include members with undernutrition and others with obesity. In more developed societies, obesity is more prevalent among the lower socioeconomic groups, especially among women. Obesity is associated with the main causes of death in Latin America (WHO, 1998). The challenge is difficult and requires an integrated effort to improve income and education of the less developed populations and additionally change the population's behavior in terms of diet and physical activity. Policies to improve income and education and to implement health promotion and preventive measures are essential to offset the economic burden of rising rates of chronic diseases. Targeting should not only consider monitoring the prevalence of this disease, but also its social distribution.

\section{References}

ALBALA, C.; VIO, F.; KAIN, J. \& UAUY, R., 2001. Nutrition transition in Latin America: The case of Chile. Nutrition Reviews, 59:170-176.

ALBALA, C.; VIO, F.; KAIN, J. \& UAUY, R., 2002. Nutrition transition in Chile. Determinants and consequences. Public Health Nutrition, 5:123-128.

ALBALA, C.; VIO, F.; OLIVARES, S. \& ANDRADE, M., 1986. Efecto de un programa de control de obesidad en mujeres de estrato socioeconómico bajo. Revista Médica de Chile, 114:934-938.

ARANCETA, J.; PEREZ-RODRIGO, C.; SERRA-MAJEM, L.; RIBAS, L.; QUILES-IZQUIERDO, J.; VIOQUE, J.; FOZ, M. \& SPANISH COLLABORATIVE GROUP FOR THE STUDY OF OBESITY, 2001. Influence of sociodemographic factors in the prevalence of obesity in Spain. The SEEDO' 97 Study. European Journal of Clinical Nutrition, 55:430-435.

ARTALEJO, F.; LOPEZ, E.; GUTIERREZ, J.; BANEGAS, J.; LAFUENTE, P. \& DOMINGUEZ, V., 2002. Changes in the prevalence of overweight and obesity and their risk factors in Spain, 1987-1997. Preventive Medicine, 34:72-81.

BARKER, D., 1994. Fetal and Infant Origins of Adult Disease. London: British Medical Journal Publishing.

BERRIOS, X., 1994. Las enfemedades crónicas del adulto y sus factores de riesgo. Un ejemplo de investigación epidemiológica. Boletín de la Escuela de Medicina, Pontificia Universidad Católica de Chile, 23:73-89.
DE ONIS, M. \& BLÖSSNER, M., 1997. WHO Global Database on Child Growth and Malnutrition. WHO/Nut 97.4. Geneva: World Health Organization.

DE ONIS, M . \& BLÖSSNER, M., 2000. Prevalence and trends of overweight among preschool children in developing countries. American Journal of Clinical Nutrition, 72:1032-1039.

DOAK, C.; ADAIR, L.; MONTEIRO, C. \& POPKIN, B., 2000. Overweight and underweight coexist within households in Brazil, China and Russia. Journal of Nutrition, 130:2965-2971.

FLORENCIO, T.; FERREIRA, H.; TOJAL, A.; CAVALCANTE, J. \& SAWAYA, A., 2001. Obesity and undernutrition in a very low income population in the city of Maceió, northeastern Brazil. British Journal of Nutrition, 86:277-283.

HOFFMAN, D., 2001. Obesity in developing countries: Causes and implications. Food, Nutrition and Agriculture, 28:35-44.

HOFFMAN, D. J.; SAWAYA, A. L.; VERRESCHI, I.; TUCKER, K. L. \& ROBERTS, S. B., 2000. Why are nutritionally stunted children at increased risk of obesity? Studies of metabolic rate and fat oxidation in shantytown children from São Paulo, Brazil. American Journal of Clinical Nutrition, 72:702-707.

INSTITUTO NACIONAL DE SALUD PUBLICA, 1999. Encuesta Nacional de Nutrición. Resultados Generales. Cuernavaca: Instituto Nacional de Salud Pública. 
JADUE, I.; VEGA, J.; ESCOBAR, M. C.; DELGADO, I.; GARRIDO, C.; LASTRA, P.; ESPEJO, F. \& PERUGA, A., 1999. Risk factors for chronic non-communicable disease: Methods and results of CARMEN program basal survey. Revista Médica de Chile, 127:1004-1013.

KAIN, J.; UAUY, R.; VIO, F. \& ALBALA, C., 2002. Trends in overweight and obesity prevalence in Chilean children: Comparison of three definitions. European Journal of Clinical Nutrition, 56:200-204.

MARTORELL, M.; KETTEL-KHAN, L.; HUGHES, M. \& GRU M MER-STRAWN, L., 1998. Obesity in Latin American women and children. Journal of Nutrition, 128:1464-1473.

MARTORELL, M.; KETTEL-KHAN, L.; HUGHES, M. \& GRUM MER-STRAWN, L., 2000. Overweight and obesity in preschool children from developing countries. International Journal of Obesity and Related Metabolic Disorders, 24:959-967.

MINSAL (Ministerio de la Salud de Chile), 2001. Encuesta de Calidad de Vida y Salud. Santiago de Chile: MINSAL.

MONTEIRO, C.; BENICIO, M.; CONDE, W. \& POPKIN, B., 2000. Shifting obesity trends in Brazil. European Journal of Clinical Nutrition, 54:342-346.

MONTEIRO, C.; MONDINI, L. \& COSTA, R., 2000. Mudanças na composição e adequação nutricional da dieta familiar nas áreas metropolitanas do Brasil (1988-1996). Revista de Saúde Pública, 34: 251-258.

MONTEIRO, C.; WOLNEY, A.; CONDE, L. \& POPKIN, B., 2001. Independent effects of income and education on the risk of obesity in the Brazilian adult population. Journal of Nutrition, 131:881S-886S.

MONTEIRO, C.; WOLNEY, A.; CONDE, L. \& POPKIN, B., 2002. Is obesity replacing or adding to undernutrition? Evidence from different social classes in Brazil. Public Health Nutrition, 5:105-112.

PEÑA, M. \& BACALLAO, J., 2000. Obesity and Poverty. A New Public Health Change. Scientific Publication 576. Washington, DC: Pan American Health Organization.

POPKIN, B., 1998. The nutrition transition and its health implications in lower-income countries. Public Health Nutrition, 1:5-22.

POPKIN, B., 2001. The nutrition transition and obesity in the developing world. Journal of Nutrition, 131:871S-873S.

POPKIN, B.; HORTON, S. \& SOOWN, K., 2001. The nutrition transition and prevention of diet-related diseases in Asia and the Pacific. Food and Nutrition Bulletin, 22(Sup. 4):11-21.
POPKIN, B.; PAERATAKUL, S.; ZHAI, F. \& GE, K., 1995. $A$ review of dietary and environmental correlates of obesity with emphasis on developing countries. Obesity Research, 3(Sup. 2):145S-153S.

POPKIN, B.; RICHARDS, M. \& MONTEIRO, C., 1996. Stunting is associated with overweight in children of four nations that are undergoing the nutrition transition. Journal of Nutrition, 126:30093016.

RIVERA, J.; BARQUERA, S.; CAM PIRANO, F.; CAM POS, I.; SAFDIE, M. \& TOVAR, V., 2002. Epidemiological and nutritional transition in Mexico: Rapid increase of non-communicable chronic diseases and obesity. Public Health Nutrition, 5:113-122.

SCHROEDER, D. G.; MARTORELL, R. \& FLORES, R., 1999. Infant and child growth and fatness and fat distribution in Guatemalan adults. American Journal of Epidemiology, 149:177-185.

SICHIERI, R., 2000. Is fat intake important in the public health control of obesity? American Journal of Clinical Nutrition, 72:203-206.

SICHEIRI, R.; SIQUEIRA, K. \& MOURA, A., 2000. Obesity and abdominal fatness associated with undernutrition early in life in a survey in Rio de Janeiro. International Journal of Obesity and Related Metabolic Disorders, 24:614-618.

UAUY, R.; ALBALA, C. \& KAIN, J., 2001. Obesity trends in Latin America: Transiting from under to overweight. Journal of Nutrition, 131:893S-899S.

VIO, F.; ALBALA, C.; OLIVARES, S. \& ANDRADE, M., 1985. Evaluación de la variación del estado nutricional en lactantes y preescolares asistentes a Centros de Recuperación Nutricional. Revista Chilena de Pediatría, 56:223-226.

WHO (World Health Organization), 1995. Physical Status: The Use and Interpretation of Anthropometry. Report of a WHO Expert Committee. WHO Technical Report Series 584. Geneva: WHO.

WHO (World Health Organization), 1998. Obesity: Pre venting and Managing the Global Epidemic. Geneva: WHO.

WOO, J.; LEUNG, H.; SHAM, A.; LAM , T. \& JANUS, E., 1999. Influence of educational level and marital status on dietary intake, obesity and other cardiovascular risk factors in a Hong Kong Chinese population. European Journal of Clinical Nutrition, 53:461-467.

Submitted on April 8, 2002

Approved on August 30, 2002 